\title{
Sets, heads, and spreading in LFG
}

\author{
Avery D. Andrews \\ Australian National University
}

\begin{abstract}
Lexical Functional Grammar (LFG) uses abstract syntactic representations (f-structures) that tend to provide less hierarchical structure for certain constructions than those employed in other formal frameworks. This produces some good results, such as a very straightforward account of feature-sharing between phrases and their heads, but also certain difficulties, especially in cases where the semantic interpreKeywords: hybrid objects, complex predicates, glue semantics, attribute spreading tation seems to be determined by the hierarchical c-structure rather than the flatter f-structure. These are unproblematic for all other major generative frameworks, but have been troublesome for standard versions of LFG.

Here I will consider two such cases: scoping adjectival modification in noun phrases; and Romance 'complex' (or 'restructuring') predicates. Problems with the semantic interpretation of these constructions were first discussed by Andrews (1983) and Alsina (1997), respectively, and by others subsequently. Both constructions exhibit the problem of apparent concentricity, and a fully satisfactory and accepted LFG solution has not yet been found. My proposal is to use the hybrid objects and distribution convention of Dalrymple and Kaplan (2000), but with singleton rather than multi-member sets, along with a facility to stipulatively suppress distribution in individual constructions. This provides an analysis which explains scope-determination and helps with certain other problems, with far less change to the theory than in previous attempts such as Andrews and Manning (1993, 1999).
\end{abstract}


LFG has traditionally proposed relatively flat covert structures (f-structures) for a variety of constructions, such as adjectival modification and 'restructuring' complex predicates, which in most other frameworks are analysed as having hierarchical covert structures, usually binary branching ones. This leads to some problems for LFG that do not arise in other frameworks: most importantly, LFG does not provide an explanation for the apparent effects of concentric constituent structure on semantic interpretation; and LFG has problems implementing the associated morphological marking.

Andrews and Manning (1993, 1999) proposed to address these problems by means of substantial modifications to the LFG architecture, but those approaches, slightly different from each other, proved difficult to generalize to other phenomena, and did not recruit many followers. Here I will propose another and considerably simpler solution, based largely on machinery that LFG already uses, or that has at least some provisional acceptance for independent reasons. The core notions are those of hybrid object and distributive versus nondistributive attributes from Dalrymple and Kaplan (2000); another is to use the filtering properties of glue in place of traditional Completeness and Coherence. This was suggested as a possibility in some of the papers in Dalrymple (1999), and later by Kuhn (2001), and is accepted by Asudeh et al. (2014) and Lowe (2015). This proposal also requires minor additions to the formalism, along with changes to some familiar analyses (such as that of attributive adjectives) and to the default annotation rules.

In the next section, I will develop the basic theoretical ideas we will need; and in the third section I will present the treatment of modal and intersective adjectives, capturing the essential points from Andrews (1983) and Andrews and Manning (1993). ${ }^{1}$ I will also analyse in LFG some material on agreement discrepancies that has recently been analysed in the Minimalist Program by Pesetsky (2013), Landau (2016) and Puškar (2017). In the fourth section, I will consider restructuring predicates in Catalan, where there is both a problem of scope in-

\footnotetext{
${ }^{1}$ We omit a treatment of what appear to be asyndetically coordinated adjectives, as in a ruthless, unscrupulous property developer, because analysing these requires a glue analysis of coordinate structures, taking us too far afield.
} 
terpretation and one of form-determination. Although Catalan seems to be generally representative of the southern Romance languages, Alsina $(1996,1997)$ and Solà $(2002)$ provide evidence that shows that the traditional LFG analysis of these constructions in Romance languages is not fully satisfactory. I conclude this section with a brief discussion of Hindi/Urdu causatives, as discussed by Lowe (2015), which are similar to Romance restructuring, but with the ordering reversed. Lowe analyses many important aspects of these constructions successfully within fully standard LFG + glue, and furthermore accomplishes the onerous task of carefully and cogently critiquing all previous analyses of restructuring complex predicates, but does not take on either scoping or form-determination.

2

HYBRID OBJEGTS, DISTRIBUTION

AND UNDERSHARING

Here we introduce the relatively new formal ideas we will need, hybrid objects and distribution, and the more recent proposal that I will call 'undersharing'. But glue semantics as presented in Dalrymple (2001) (the 'new glue' version) will be assumed, and not described here.

Distribution vs. 'sharing'

The notion of distributive attribute was introduced by Bresnan et al. (1985), and was further developed by Kaplan and Maxwell (1988). Distributive attributes, when attributed to a set in an f-structure, are in effect attributed to all the members of that set, and vice versa, allowing for the satisfaction of the Completeness and Coherence Constraints in examples such as John bought and read the book.

The formulation of distribution that we shall assume is from Dalrymple (2001, p. 158), and is slightly different from earlier ones such as Dalrymple and Kaplan (2000):

(1) For any distributive attribute $A$ and set $s, A(s)=V$ iff $\forall f \in s$, $A(f)=V$.

To see how this works, consider a structure such as (2) below, where the attribute $\mathrm{F}$ is distributive, and the outer square brackets signify that the entire structure is actually a 'hybrid object' as we discuss in the next subsection, with both set-members, and, possibly, attributes: 
(2)

$$
\left[\left\{\begin{array}{ll}
{\left[\begin{array}{ll}
\mathrm{F} & Y
\end{array}\right]} \\
{\left[\begin{array}{ll}
\mathrm{F} & Z
\end{array}\right]}
\end{array}\right\}\right]
$$

As long as nothing ascribes any F-value to the entire structure, it is possible that $Y \neq Z$. But if something ascribes a value $X$ for $\mathrm{F}$ to the entire structure, then (2) must become more highly specified as indicated in (3) below ( $X$ is to be read as a shared value, rather than multiple copies, and the issue of whether $X$ should or should not be written at the top level will be discussed shortly):

(3)

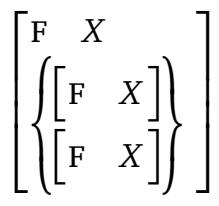

And if this is impossible, due to $Y$ and $Z$ being contradictory, then there is no solution: there is no well-formed sentence structure that includes the f-structure. This is exactly the effect we want in coordinate structures, where grammatical relations are sometimes shared and sometimes not:

(4) a. Mary praised Bill and criticized John

b.

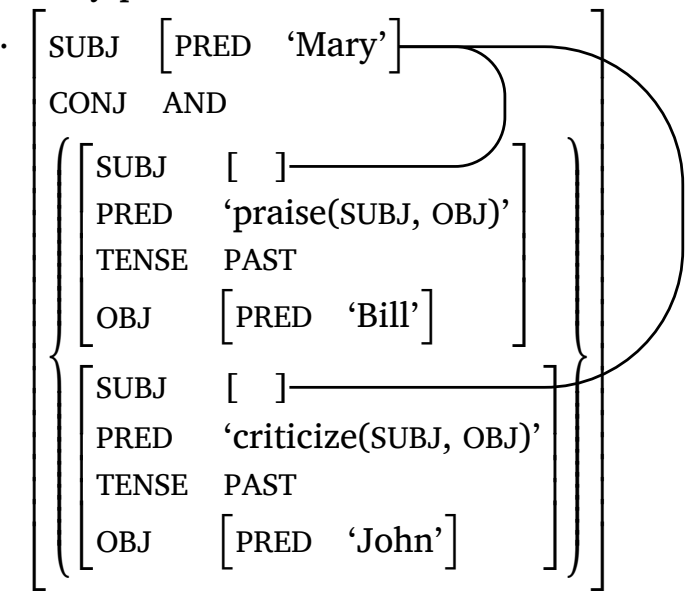

In this case, SUBJ is supposed to be shared and OBJ is not, but other possibilities are both or neither:

(5) a. Mary praised Bill and Susan praised John.

b. Mary (both) praised and criticized John. 
The distributivity convention (1) handles this and also other issues associated with coordinate structures; whereas the CONJ attribute in (4b) is nondistributive, and so is not shared amongst the conjuncts.

A further property of (1) is that if the values of $\mathrm{F}$ in the set members are specified as being the same by virtue of their internal structure, then this becomes the value of $\mathrm{F}$ for the entire structure as well, for the satisfaction of constraining equations. In the case of grammatical relations in coordinate structures, this will never happen due to the Predicate Indexing convention (all instances of PRED-values are taken as distinct, even if they represent the same choice from the lexicon), but it can occur for ordinary feature-values. In effect, distribution works the same way for defining specifications (those that impose a feature-value) applied to the whole and for constraining specifications (those that check that something else has put a given value somewhere).

Formulating the Coherence Constraint for the representation of (4b) is problematic. In the structures such as example (30) in Dalrymple (2001, p. 373), the distributed GFs are not explicitly represented at the upper level, perhaps on the basis that they are not 'really' present there, but are only 'virtually' present by the formulation of the definition (1), so that Coherence will work as usual. This can work for coordinate structures, since the lexical items calling for the grammatical functions are always located in the set members rather than in the whole structure. But in our analysis of complex predicates, grammatical relation attributes will be scattered across the levels of the set-inclusion structure, so we need to say something definite about this situation. One possibility would be to elaborate the definition of Coherence to deal with this; a simpler way is to dispense with the Coherence and Completeness Constraints in their original form, and let glue assembly do their work, as has been occasionally suggested since Kuhn (2001) if not before, and is accepted by Lowe (2015, p. 426). ${ }^{2}$

However, whether or not we abandon Completeness and Coherence, we have another problem with coordinate structures: the 'resource deficit' discussed by Dalrymple (2001, pp. 377-378) and Asudeh and Crouch (2002). The meaning resource provided by the subject in (4) needs to be consumed by two verbs, whereas by lin-

\footnotetext{
${ }^{2}$ The representational issue is addressed in greater detail in Appendix A.
} 
ear logic, when one verb uses it, it is gone, and not available to the other. Asudeh and Crouch propose a solution that is notationally very complex, but works, and can be provisionally accepted here.

The behaviour of distribution when the set is a singleton has been somewhat overlooked. A distributive feature will always be distributed, and therefore in effect shared. In (6a), for example, $X$ is the value of $\mathrm{F}$ in every member of the hybrid object's set, so (6a) comes out identical in its properties to (6b):

(6) a. $\left[\left\{\left[\begin{array}{ll}F & X\end{array}\right]\right\}\right]$

b. $\left[\begin{array}{ll}\mathrm{F} & X \\ \left\{\left[\begin{array}{ll}\mathrm{F} & X\end{array}\right]\right\}\end{array}\right]$

Distribution therefore produces effects very similar to the sharing of attributes used by Andrews and Manning (1993, 1999), but in a more limited way, and without any fundamental change to the formal framework beyond what is independently proposed for coordinate structures.

Hybrid objects were originally proposed by John Maxwell and introduced into the LFG literature by Dalrymple and Kaplan (2000, see esp. p. 778). A hybrid object is an f-structure that has not only members and distributive attributes, but can also have 'nondistributive' attributes that apply to the entire structure but that do not obey the distribution convention (1).

Person and number were the most important originally motivated nondistributive attributes. These are motivated by coordinate structures such as José y yo in Spanish, where both conjuncts are singular, but the whole NP is plural; and where one conjunct is first person, the other third, while the whole is first person:

(7) José y yo hablamos.

José and I talk.1PL(PRES or PRET)

'Jose and I talk/talked.'

Dalrymple and Kaplan propose the following f-structure for the NP (they omit the CONJ feature without discussion): 
(8)

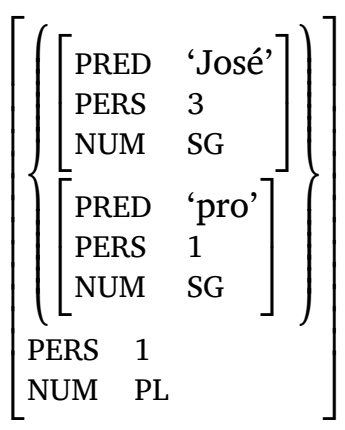

The values of NUM and PERS for the entire structure do not appear in all of the individual conjuncts, although the PERS-value does appear in one of them.

For Dalrymple and Kaplan's purposes, it is at least plausible that there is a universal classification of features into distributive and nondistributive (although, as we shall see, this is not entirely free of problems), but for the wider application of distribution that we are attempting here, this is unfortunately not possible. Rather, it seems necessary to stipulate on a construction-specific basis that certain features are not distributed.

Although it is not the only possibility, I propose that:

(9) a. Certain attributes, particularly ADJUNCT and CONJ (and possibly PRED) are universally non-distributive. In situations where they might appear to be distributive, some other analysis is correct, such as the use of functional uncertainty (no such cases are suggested here).

b. Other attributes are distributive by default, but these can be blocked from distribution by what I will call an 'undersharing' specification, as detailed below. In such cases, there is plentiful and overt positive evidence that the undershared attribute is behaving differently from the ones that are behaving distributively.

'Undersharing' as notated and used here is an innovation of this paper; but construction-specific stipulation of distributivity for attributes was suggested by Belayev et al. (2015).

\section{ATTRIBUTIVE ADJEGTIVES AND NP STRUGTURE}

We now consider the relative scope of adjectival modifiers, first discussed by Andrews (1983) as an objection to the flat structure analyses 
of Jackendoff (1977). This material, entirely unproblematic in most generative frameworks, was treated in the heavily modified version of LFG used in Andrews and Manning (1993), but not in the somewhat differently modified version of Andrews and Manning (1999). In the first subsection we consider the interactions of relative order and scope in English, with special attention to 'modal' adjectives such as former and alleged; in the second, we provide an analysis; in the third we discuss coordination and the need for undersharing stipulations; and in the fourth, we discuss the phenomenon of 'agreement mismatches' in certain other languages that provides additional motivation for the present approach.

Adjectives and scope

LFG has generally followed the 'flat structure' approach to adjectival modifiers advocated by Jackendoff (1977), e.g. Dalrymple (2001, pp. 256-257). The adjectives are introduced in APs whose f-structure correspondents are members of the set-valued attribute ADJUNCTS, yielding an annotated c-structure as follows for a tall Swedish man: ${ }^{3,4}$

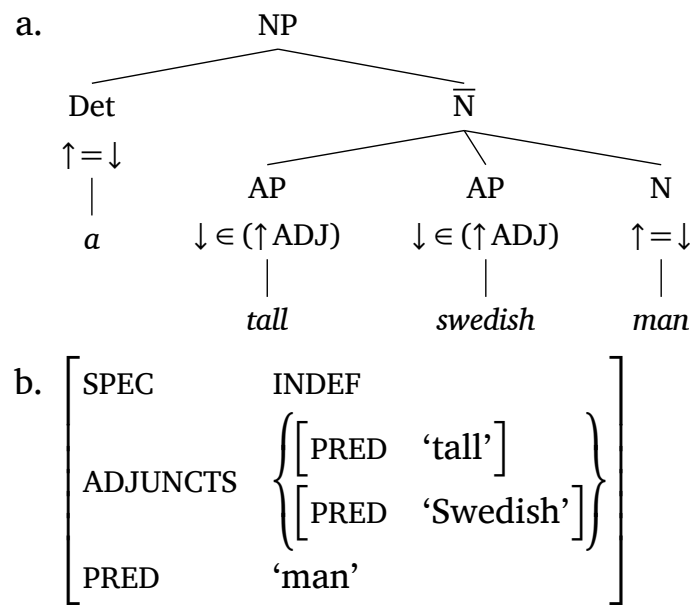

This flat $\mathrm{f}$-structure works well for intersective adjectives, as treated in considerable detail by Dalrymple. It can be extended to at least some

\footnotetext{
${ }^{3}$ Dalrymple (2001, p. 257) omits from the structure the topmost NP layer with the determiner.

${ }^{4}$ Note that the set-values of ADJUNCTS have never been argued to be hybrid objects, so we seem to have an implicit distinction between hybrid objects and 'pure sets', which would not be able to have nondistributive attributes.
} 
subsectives, such as skillful, by treating them as taking an unexpressed $a s$-argument. This is usually supplied by the head noun when the adjective is in attributive position, but is fundamentally always supplied by context, most obviously so when the adjective is predicative: ${ }^{5}$

(11) a. Brett is a skillful surgeon, but not much of a pilot.

b. Wow, he's skillful! [meaning: as a surgeon, watching Brett in the operating theater and implying nothing about his piloting skills]

c. Can we find any good linguists? [meaning: good at basketball, for an interdepartmental tournament $]^{6}$

This analysis fails to give a fully satisfactory account of 'modal' adjectives such as former and alleged, because, although Dalrymple's glue treatment works when there are no other modifiers, such as former in former senator, it doesn't account for the effect of ordering on interpretation when there are multiple modifiers:

(12) a. He is an unscrupulous former property-developer.

b. He is a former unscrupulous property-developer.

The first characterizes his career as a developer as having existed in the past, but his unscrupulousness as persisting, while the second locates both in the past, so that he could well now be a comprehensively reformed character. We also note that $\mathrm{He}$ is a formerly unscrupulous property developer means that he's still a developer, but is no longer an unscrupulous one. When former is replaced by its adverbial variant, the attribution to past time applies only to the adjective, not the entire adj + noun combination (as is captured by Dalrymple's analysis of adverbs modifying attributive adjectives).

The problem for current LFG is that even if we adopt nested cstructures such as (13a) below, the f-structures will still be flat, because the $\bar{N}$ s have to be introduced with $\uparrow=\downarrow$ annotations in order for the LFG analyses of agreement to work in examples such as this/*these

\footnotetext{
${ }^{5}$ There are also 'pseudo-modal' adjectives such as fake, which Partee (2010) analyses as being actually intersective, but exhibiting modal-like behaviour due to pragmatic accommodation effects.

${ }^{6}$ This example, which illustrates the essentially contextual nature of the phenomenon, is due ultimately to Georgia Green, and was pointed out to me by an anonymous reviewer.
} 
former developer. So from a tree like (a) below, we still get the same form of structure as (10b), with the modifiers in an unstructured set that does not express the scope relations:

(13) a.
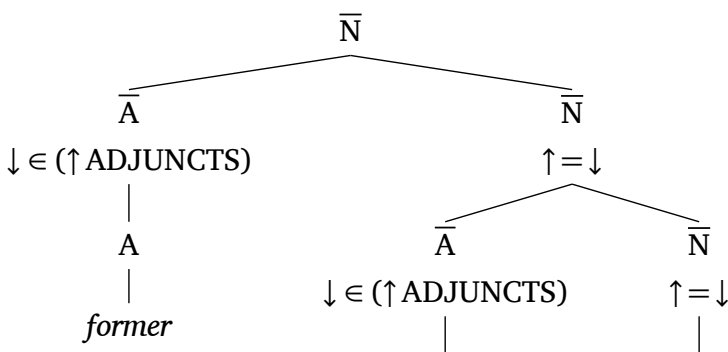

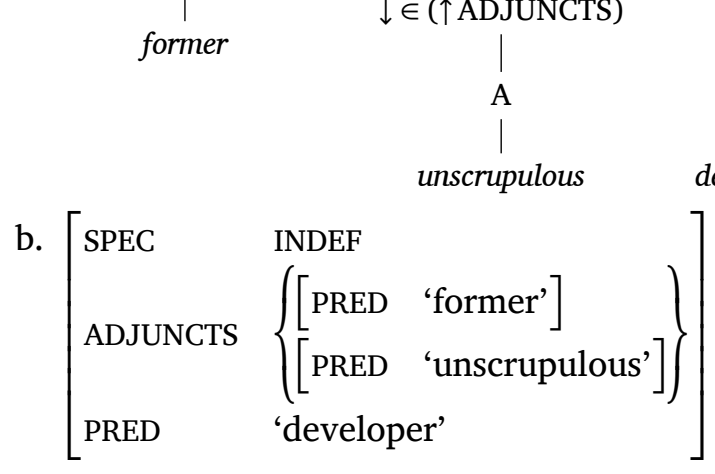

These structures could be interpreted using 'f-precedence' (Dalrymple 2001, 171-182), but Andrews (1983) shows that this introduces a problem: it is the order of concentricity out from the head that matters, rather than linear string order (as demonstrated by the behaviour of postnominal modifiers). For example, a supposed American businessman and an American supposed businessman are interpreted in the same way that the examples of (12) are, but (14) may be interpreted either way: ${ }^{7}$

(14) a supposed businessman from America

The interpretational problem is made concrete in the glue analysis of Dalrymple (2001, ch. 10), where the meaning-constructors for the modifiers will be able to operate on the two modifiers in either order,

\footnotetext{
${ }^{7}$ Sadler and Arnold (1994, p. 196) find that postnominal adjectives scope over prenominal ones, but they do not consider PPs, for which this does not appear to be the case, creating a problem for their interesting structural proposal. A possible account of the scope behaviour of postnominal APs is that that they are adjoined to DP in the manner argued for relative clauses by Vergnaud (1974) on the basis of examples such as a man and a woman (who are) similar in their interests have a chance of getting along reasonably well.
} 
wrongly representing both sentences of (12) as ambiguous in the same way that (14) is.

To resolve this problem, I propose to use hybrid objects and distribution to support modification of the f-structures so as to follow the c-structure more closely. Then, glue or any other reasonable form of syntax-semantics interface can produce the correct interpretations without difficulties.

\section{Nesting structures}

The f-structures I propose for the sentences of (12) are:

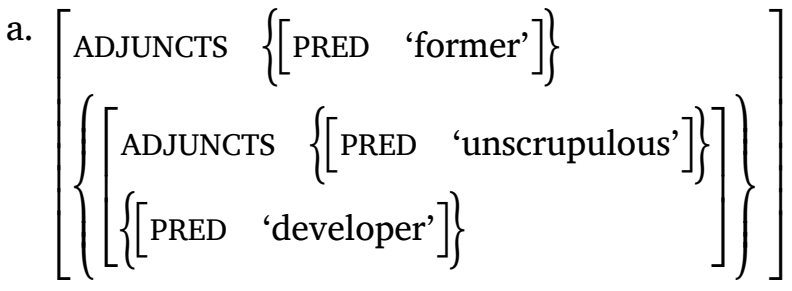

$$
\begin{aligned}
& \text { b. }[\text { ADJUNCTS }\{[\text { PRED 'unscrupulous' }]\}] \\
& \left.\left\{\left[\begin{array}{l}
\text { ADJUNCTS }\left\{\left[\begin{array}{ll}
\text { PRED } & \text { 'former' }
\end{array}\right]\right\} \\
\left\{\left[\begin{array}{ll}
\text { PRED } & \text { 'developer' }
\end{array}\right]\right\}
\end{array}\right]\right\}\right)
\end{aligned}
$$

These use hybrid objects with singleton sets to preserve the information from the c-structure, and will be produced if the $\overline{\mathrm{N}}$ expansions introducing the APs introduce their lower $\bar{N} s$ with a $\downarrow \in \uparrow$ annotation rather than the usual $\uparrow=\downarrow$ :

(16) a.

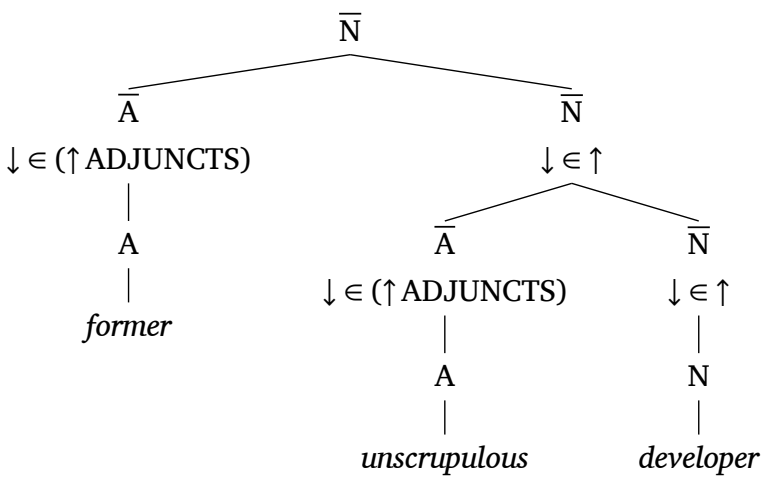


b.

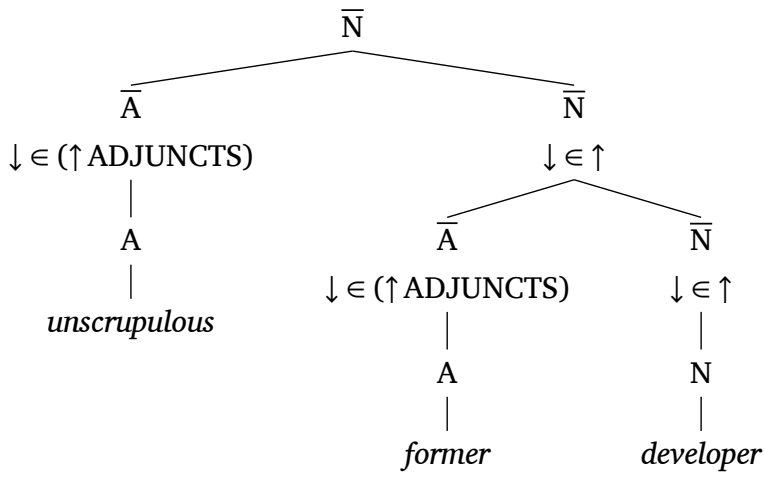

For this to work, we need to assume that ADJUNCTS is non-distributive. To simplify the structures, we will also assume that PRED is nondistributive, but this assumption is not necessary and may be incorrect, as will be briefly discussed in the conclusion of this paper.

These structures provide a basis for semantic interpretation of these modifiers, which can be given with glue semantics, adapting the treatment of Dalrymple (2001). A brief description is provided in Appendix B, and we can explain the ambiguity of (14) in the obvious way by extending the phrase structure rules to expand $\overline{\mathrm{N}}$ to $\overline{\mathrm{N}} \mathrm{PP}$. These structures also account for other well-known properties of adjectival modification, such as that 'inner' adjectives cannot be ordered in front of intersective/subsective or modal adjectives:

(17) a. John is a tall/purported chemical engineer.

b. *John is a chemical tall/purported engineer.

There are further issues in adjective ordering to which the present proposals are relevant; but we turn instead to some phenomena of agreement and some issues concerning distribution.

As discussed in connection with example (7), Dalrymple and Kaplan assumed that the features of person, gender and number were nondistributive, because these features did not appear to be shared between the members of a coordinate structure and the whole. Subsequently, on the basis of previous work in HPSG and scholarship in various languages, especially Slavic ones, Wechsler and Zlatič $(2000,2003)$ made a strong case that agreement features should appear, often doubly, under under two sub-attributes, INDEX and CONCORD, the first primarily 
involved in verb agreement, the second in concord within the NP. Person features seem to be restricted to INDEX, while gender and number are proposed to appear in both, usually with the same value, but sometimes different, in order to explain various agreement mismatches.

King and Dalrymple (2004) adapted and used these ideas to explain phenomena such as the apparent agreement anomaly in coordinations that are sometimes called 'close coordination', where there are two nominal phrases with different reference, but only one demonstrative that applies to both:

(18) a. This cat and dog are $/ *$ is friends.

b. "These cat and dog is/are friends.

They concluded that in English (specifically, as other languages differ), demonstrative pronouns show CONCORD agreement, which they proposed to be distributive, so that the demonstrative is singular, agreeing with the nominal heads of the two conjuncts. They further conclude that INDEX is nondistributive, and in this case is assigned on a semantic basis, so that the verb agreement is plural. Their structure (20) (p. 77) can be represented as (19) using our conventions:

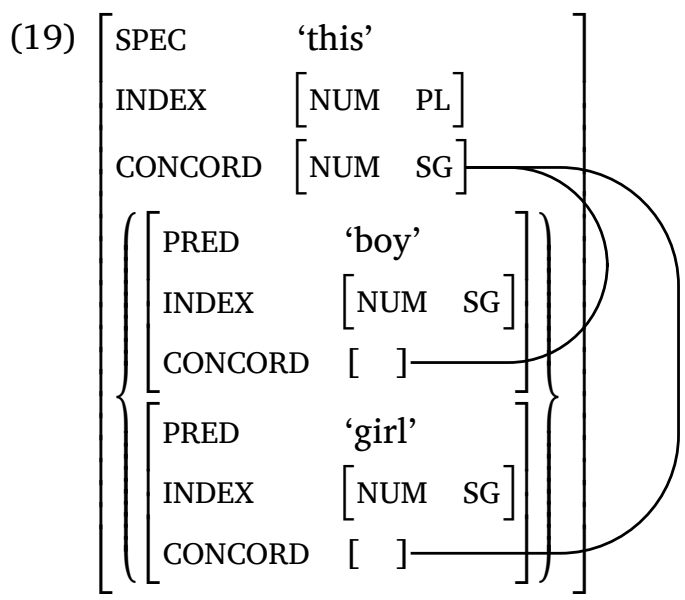

However, our proposed change in NP structure requires both kinds of features to be distributive. For as per Wechsler (2011), most nouns impose identity between the INDEX and CONCORD values of features, with equations such as ( $\uparrow$ CONCORD NUM) $=(\uparrow I N D E X$ NUM). This does not create a problem with the traditional LFG flat structures for NPs, but does with our present proposal, unless both attributes are distributive. 
Were this not the case, the agreements wouldn't work in sentences like this:

(20) These alleged murderers are/*is surely guilty

The noun murderers would introduce a NUM PL feature and share it between INDEX and CONCORD; by the distributivity of CONCORD it would wind up on the demonstrative, but by the non-distributivity of INDEX it would not be passed up to the higher levels of the NP, and so singular agreement on the verb would be expected, instead of the plural that is actually required.

We therefore need to stipulate nondistributivity of INDEX in the close coordination construction. For this we propose to use the restriction notation from Kaplan and Wedekind (1993), in a rule like this:
$\bar{N}$

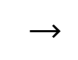
$\overline{\mathrm{N}}^{+}$
$\downarrow \in \uparrow /$ INDEX
Cnj
$\overline{\mathrm{N}}$ $\downarrow \in \uparrow /$ INDEX

Consistently with its original use, the notation says that the f-structure of the upper $\overline{\mathrm{N}}$ is the same as that of the daughters, except for the universally nondistributive attributes such as ADJUNCTS, and, in addition, the normally distributive INDEX attribute. Without such a stipulation, the distribution convention would cause the plural agreement of the verb to propagate into the conjuncts, and then be transmitted to their CONCORD-values and expressed morphologically. A similar undersharing specification is needed for the full NP/DP coordination rule, of which a preliminary version can be formed by replacing $\overline{\mathrm{N}}$ with NP or DP in (21) above.

Such undersharing specifications are theoretically somewhat undesirable, but there is independent evidence that they are necessary. Dalrymple and Kaplan (2000, pp. 771-773) discuss the case of Xhosa, where the conjuncts of coordinated NPs have to agree in 'noun class' if anything agrees with them (but can disagree if nothing does):
a. Umtwana
uyagoduka.
(1/2GEND.SG)child (1/2GEND.SG)is going home
'The child is going home.'
b. umfana nomfazi

(1/2GEND.SG)young man (AND.1/2GEND.SG)woman bayagoduka.

(1/2GEND.PL)are going home

'The young man and the woman are going home.' 

c. *igqira nesanuse \{a|zi-\}yagoduka.
(5/6)doctor (AND.7/8)diviner $\{(5 / 6 \mid 7 / 8$ - $\}$ go home
trying to say: 'The doctor and the diviner went home.'
d. Igquira li-yagoduka nesanuse.
(5/6).doctor 5/6-is going home (AND.7/8)diviner
'The doctor is going home with the diviner.'
e. Isanuse si-yagoduka niguireanumber (7/8).diviner 7/8-is going home (AND.5/6).doctor 'The diviner is going home with the doctor.'

Sentence (a) illustrates agreement with a singular, noncoordinated noun; (b) with a coordinated noun where the conjuncts have the same gender; (c) the failure of such a case where the genders differ; $(d, e)$ an alternate construction that can be used when the 'classes' differ.

Their proposal is that these examples involve a distributive attribute 'class' rather than nondistributive gender, but distributivity appears to be the only respect in which 'class' is clearly different from gender. Indeed, in his discussion of the Bantu 'class' system, Corbett (1991, pp. 43-46) notes that in early Bantu work, 'class' referred to the combinations of a kind of gender with number, so that 'animate' singular was class 1 , animate plural class 2 , etc. But this view accords too little recognition to the regular relation between the semantically singular and plural classes, which indicates that the gender-like property should be dissociated from number, which is further supported by examples like (b) above, where two class 1 nouns trigger agreement by a class 2 prefix.

Corbett thereby distinguishes gender from number, and designates such postulated genders as ' $1 / 2$ ' and ' $3 / 4$ ', based on the original class terminology. This notation maintains a convenient and useful amount of contact with the earlier tradition, while providing more satisfactory analyses. Corbett calls these categories genders, and their only apparent difference from familiar traditional genders is their different behaviour with respect to distribution. Since the traditional Bantu class pairs seem to show no major differences besides behaviour under distribution from other putative genders, there is no basis for treating them as a different kind of attribute. ${ }^{8}$ Therefore distribution

\footnotetext{
${ }^{8}$ Another possible difference, pointed out by an anonymous referee, is that gender is subject to resolution and class is not. But resolution is an extremely
} 
is not a sufficient basis for distinguishing Bantu 'slashed classes' from other instances of gender.

Instead, I suggest that gender is normally undershared in coordinate structures, presumably for the functional reason that this allows a wider range of coordinations to be generated. However, such an undersharing stipulation happens to be absent from Xhosa (the availability of a semantically approximately equivalent comitative construction might be a relevant factor). This treatment is better motivated if we can find other kinds of situations that can be well-analyed as stipulated undersharing, to which we turn in the next subsection.

Pesetsky (2013), Ouwayda (2014), Landau (2016) and Puškar (2017) discussed another kind of phenomenon that can be analysed in terms of stipulated nondistributivity involving singleton sets. The treatment here is brief, due to the number of languages involved that don't seem to have much in the way of relevant previous work in LFG, but the phenomena are striking.

The basic phenomenon is that either gender or number agreement within an NP shifts from grammatical (as determined by the head) to semantic. Sentence (a) below is a Russian example involving case, while sentence (b) is a Modern Hebrew example involving number:

a. U nas byl-a očen xoroš-aja zubn-oi vrač-ъ. of us was-FEM very good-FEM dental-MASC doctor-MASC 'We had a very good female dentist.' (Pesetsky (2013, p. 38), citing earlier work)

b. ha-be'alim ha-pratiyim ha-axaron šel ha-tmuna the-owner(PL) the-private(PL) the-last(SG) Pos the-painting haya was(SG)

'The last private owner of the painting was [the psychoanalyst Jacques Lacan].' (Landau (2016, p. 1005); naturally occurring example from Wikipedia)

complex phenomenon, to the extent that one can actually doubt whether it really exists as a concept of grammatical theory, and our knowledge of the Bantu languages with noun class is relatively limited. Therefore, I do not find this to be a clear difference. 
The background to (a) is that in Russian, professional nouns are invariably masculine in their grammatical gender, as shown by the masculine agreement of the adjective zubnoj, but if the referent is female, the gender has the possibility of switching (it can also stay masculine, or switch at various places). In (b), the background is that the word be'alim in Hebrew is grammatically plural but can have singular reference, but if the reference is singular, adjectives and the main predicate can switch to singular. A significant commonality between both examples is that if a switch occurs overtly in the nominal, the verb must follow suit, and, within the nominal, the switch must obey the concentricity hierarchy: if a more inner element switches, all the more outer ones must switch too, with opposite linear order in the two languages. This also happens with the other case of agreement discontinuities discussed by both Landau and Puškar: gender (class) agreement in Chichewa. ${ }^{9}$

An initial thought might be that we could use INDEX and CONCORD to analyse this, and indeed Landau provides such an analysis within the Minimalist Program. But given the flat structures of current LFG, INDEX and CONCORD don't help, because both attributes will be attributes of the same f-structure. Therefore, if they are equated or nonequated anywhere in that structure, they will be so equated or nonequated everywhere, providing no basis for explaining concentricity.

We can do better with nesting of singleton sets and undersharing. First, a note on 'grammatical' versus 'semantic' agreement: crosslinguistically, agreeing modifiers will almost always show 'grammatical' agreement if they are modifying something with grammatical gender or number (pluralia tantum), but will show 'semantic' agreement if there is no overt grammatical agreement trigger, as seen in these examples from Modern Greek:

a. I arsenikí arákhni huntsman fénete na méni

the(F) male(F) spider(F) huntsman seems to remain akíniti ke eksouthenoméni.

motionless(F) and exhausted(F)

'The male huntsman spider seems to remain motionless and exhausted. 10

\footnotetext{
${ }^{9}$ These concentricity effects are currently treated in the Minimalist Program as an aspect of the 'Agreement Hierarchy' of Corbett (1979).

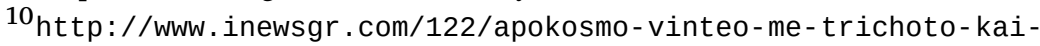


b. Íme étimi.

I am ready(F)

'I am ready (female speaking, not male).'

The LFG + glue literature does not provide an explicit account of how semantic agreement works/integrates with syntactic agreement; the nearest approach being Wechsler (2011) in a non-glue LFG formulation. The following, based on Wechsler, seems workable: ${ }^{11}$

(25) a. Grammatical gender and number associated with nouns are introduced by defining equations on the lexical entries of those nouns, without meaning-constructors specific to the features.

b. Semantically transparent gender and number associated with nouns are introduced on those nouns by defining equations with associated meaning-constructors.

c. Agreeing items all have free choice between:

i) introducing a constraining equation with no meaning constructor (grammatical agreement),

ii) introducing a defining equation with a semantically appropriate meaning-constructor (semantic agreement).

For work relevant to the distinction between (a) and (b) in Greek, see Merchant (2014) and Alexiadou (2017). Rule (c) implies that lexical entries of agreeing items such as étimi 'ready'(Fem.Nom.Sg) all have disjunctive specifications; this is notationally a bit awkward but can be done with 'templates' (a kind of macro used in LFG, as briefly discussed below), and is similar to the 'Agreement Marking Principle' of Wechsler (2011, p. 1009).

As exemplification of the proposed principles, in (24b), the adjective étimi 'ready' would have a defining equation and a feminine gender meaning-constructor; whereas in (24a), the noun arákhni 'spider' would have a defining equation for feminine gender without any associated meaning-constructor, while the other adjectives would have constraining equations for gender, once again without meaningconstructors.

tromaktiko-plasma-prokalei-anatrichila-sto-internet.htm; viewed Jan 12, 2018.

${ }^{11}$ Note that the notationally complex disjunction in (c) can be managed with templates. 
To get the Russian agreement discontinuity, we use an alternate expansion of NP that undershares GENDER in CONCORD and INDEX (unfortunately, we need to do both). There is a further restriction: these discontinuities can only happen in the nominative case, leading to the following rule:

(26) NP $\rightarrow$

$$
\begin{gathered}
\text { NP } \\
(\uparrow C A S E)=\text { NOM } \\
\downarrow \in \uparrow /(\text { CONCORD } \mid \text { INDEX }) \text { GEND }
\end{gathered}
$$

The use of the typically disjunctive 'l' symbol is motivated by the consideration that a gender feature is not distributed if it lies in either the INDEX or the CONCORD bundle. We need to do this in order to change both the presumably INDEX agreement on a main verbal predicate such as byl-a 'was-F' and an adjectival one such as xoroš-aja 'good$F^{\prime}$ in (23a). The rule (26) only has a discernable effect in singular NPs because the genders are neutralized in the plural. When (26) applies, any higher agreeing items will have to have their gender features interpreted semantically. Another, technical, point is that for (26) not to run afoul of the offline parsability constraint (Kaplan and Bresnan 1982, p. 266), we need to adapt the constraint so as to allow a node of type $\mathrm{X}$ to dominate another node of type $\mathrm{X}$ as long as they introduce different annotations.

Conclusion

We have applied hybrid objects with singleton sets to adjectival modification constructions, proposing a solution to issues that have remained largely unsolved in LFG. A further, general observation is that per conventional LFG + glue, we should expect that the linear or hierarchical arrangement of modifiers would normally impose no solid restriction on interpretation, in a way comparable to what we often find with quantifier scope. As far as I am aware, this is extremely rare or nonexistent with modifiers, and the sensitivity of scope to concentric arrangement extends to somewhat exotic constructions such as the Modern Greek 'polydefinite' construction (Velegrakis 2011, esp. pp. 31-35).

Nordlinger and Sadler (2008) and Sadler and Nordlinger (2010) proposed applying sets to NP structure, in Australian languages. They do not use singleton sets, but do have problems with making distribution work; the undersharing mechanism proposed here could help. 
Romance complex ('restructuring') predicates pose a classic problem. On the one hand, they are 'monoclausal', as evidenced by clitic climbing and other phenomena that seem to show that they constitute a single clause. On the other hand, they demonstrate 'respect for the tree': both their interpretation and the distribution of their verbal markers appear to depend on the tree structure, ${ }^{12}$ both of which are problematic for LFG, which assumes that both verbs inhabit a single clause in f-structure. These points are illustrated by these examples from Catalan (Alsina p.c.), repeated from Andrews (2007):
a. L' acabo de fer llegir al nen. it I.finish of make.INF read.INF to the boy 'I just made/I finish making the boy read it.'

b. La faig acabar de llegir al nen. it.F I.make finish.INF of read.INF to the boy 'I make the boy finish reading it (say, a map ([GND FEM])).'

Here, the final verb is generally considered to be the 'main' verb, whereas the (two) preceding ones would be considered 'light' verbs.

The appearance of clitics $L$ ' (gender-ambiguous) and La expressing an argument of the main verb on the first light verb provides one of the arguments that the construction is monoclausal. The other is that the arrays of the arguments of the individual verbs appear to be combined into one, which obeys the rules for the array of grammatical relations for transitive and ditransitive predicates. In particular, the boy, the Agent and expected subject of the Caused verb, is expressed as an $a$-object, the normal grammatical relation for the Recipient of a ditransitive, and there is only one bare NP object, as occurs regularly in the Romance languages.

Various other languages combine indications of, on the one hand, hierarchical embedding of the structure headed by the Caused verb within one headed by the Causer verb, and, on the other, fusion of the two levels of the structure into something that appears for at least some purposes to be a single clause. An important example in the LFG

\footnotetext{
${ }^{12}$ The linear order is another possibility, but this doesn't seem to be workable, and there would be no explanation for why the relevant linear order is reversed for Hindi/Urdu, as discussed below.
} 
literature has been Hindi/Urdu (Butt 1995), most recently analysed within LFG + glue by Lowe (2015). He proposes (p. 442) the f-structure of (28b) for the example (28a):
a. Amu-ne bacce-se
haathii pinc

Amu-ERG child.OBL-INSTR elephant pinch

kaar-vaa-yaa.

do-CAUSE-PERF.MSG

'Amu caused the child to pinch the elephant.'

b. $\left[\begin{array}{lll}\text { PRED } & \text { 'pinch' } \\ \text { CAUSE } & + & \\ \text { SUBJ } & {[\text { PRED }} & \text { 'Amu' }] \\ \text { OBJ } & {[\text { PRED }} & \text { 'elephant' }\end{array}\right]$

The PRED-value is the main verb; the causative verb is represented as a non-PRED feature value; and glue semantics is used to get the grammatical relations correctly associated with their semantic roles. This single-layer f-structure analysis, which we could describe as 'fully monoclausal' due to having only a single layer of f-structure like an ordinary simple clause, works reasonably well for Hindi/Urdu; whereas in Romance languages, such an analysis is more problematic, as we discuss in the next section.

\subsection{Problems with the fully monoclausal analysis}

There are three problems: the determination of forms, the multiplicity of light verbs, and the relevance of order. We consider each in turn.

In Romance languages ${ }^{13}$ an infinitive may appear with or without an additional verb marker such as $a$ or de, while some verbs instead take a present or past participle without any additional marker. Taking as examples (27) and (33), we find the following form determinations:

(29) a. acabar 'finish' is followed by de+infinitive

b. fer 'cause/make' is followed by a bare infinitive

c. poder 'can' is followed by a bare infinitive

\footnotetext{
${ }^{13}$ There is a form-determination problem in Urdu, discussed later; it is much more limited than in Romance, and does not provide as much difficulty for LFG.
} 
d. haver 'perfect auxiliary' is followed by a past participle

e. anar 'go to' is followed by $a+$ infinitive

Solà (2002) provides many more examples. The original solution to this problem was to add an additional projection called m-structure (Butt et al. 1996, Butt et al. 1999). This can be made to work, but has not fared very well, as we now discuss.

M-structure was originally proposed to be a projection directly from c-structure, and could be thought of as a kind of enrichment of the c-structure that includes certain inflectional features, in particular the ones that light verbs impose on their 'semantic complements', which follow them in Romance languages. The lexical entries of verbs would put their verbal form and marker features on m-structure, and the c-structure rules would specify the m-structure of a VP complement as the 'DEP'-value of the m-structure of its containing VP. Light verbs would furthermore specify what features their DEP-values should contain. Example (33c) below would then have the following c- and $\mathrm{m}$ - structures, where the correspondence is indicated by numerical superscripts rather than dotted lines in order to reduce clutter:

(30) a.

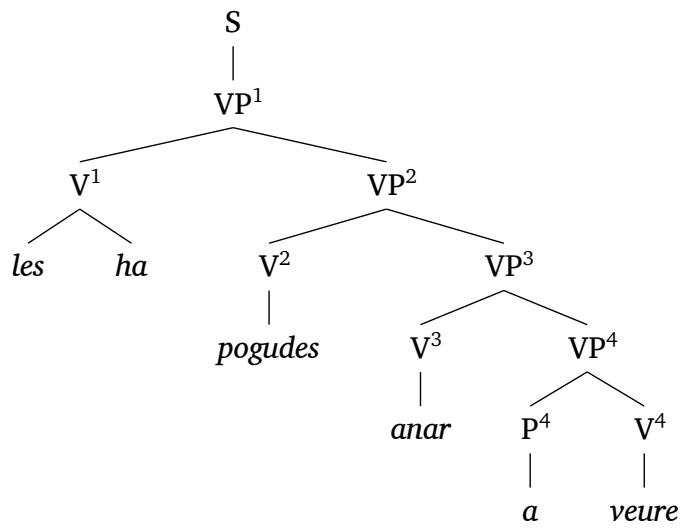

b.

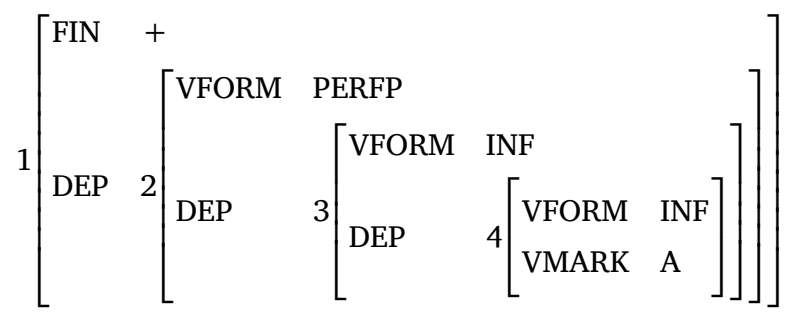


Such structures are provided by appropriate placement of annotations like these in the phrase-structure rules, where ' $*$ ' means the c-structure node the annotation appears on, ' $\hat{*}$ ' the mother of that node, and $\mathrm{m}_{\mathrm{m}}$ the $\mathrm{m}$-structure of the node referred to:
a. $\left(\hat{*}_{\mathrm{m}} \mathrm{DEP}\right)=*_{\mathrm{m}}$
b. $\hat{*}_{\mathrm{m}}=*_{\mathrm{m}}$

Since the m-structure comes off c-structure rather than f-structure, it is not a problem if the f-structure is flat. Note also that the clitic pronoun les does not appear in the $\mathrm{m}$-structure, because $\mathrm{m}$-structure is not a full representation of the hierarchical structure of a sentence, and, in particular, does not include the grammatical relations. If the clitic did have an m-structure, it would be disconnected from that of the verbs.

M-structure does what it is supposed to do, but comes at a certain cost. First, we have an entire additional projection for which relatively few additional uses have been proposed, and for which there is no motivation whatsoever in many languages, including richly inflected ones such as Greek or Icelandic (their causatives are either fully morphological or unambiguously biclausal). Indeed, this projection now perhaps has no current uses at all in its original form, as an independent projection from c-structure. For example, Belayev (2013) applies a concept of m-structure to person agreement in the East Caucasian language Dargwa, but he uses the proposal of Frank and Zaenen (2004) that m-structure comes off f-structure rather than c-structure. Frank and Zaenen manage to make this proposal work for French, where there is reasonable evidence that the light verbs are introduced in a verbal cluster that does not include any verbal complements, and they are restricted to a small number of auxiliaries. But it is very hard to imagine how their proposal could extend to southern Romance languages, where not only is the VP-complement 'right-branching structure' well argued for and generally accepted (e.g. Manning 1996, Alsina 1997), but also, the inventory of light verbs is much larger, and not confined to any class that could reasonably be described as 'auxiliaries'.

This leads to our second problem. Solà (2002, pp. 227-229) gives a substantial but not complete collection of restructuring verbs. In addition to various aspectual concepts and the verbs 'come' and 'go', 
the collection contains 'learn', 'go up' (to do something) and 'pass by' (to do something), yielding examples such as these:

a. Ho he après a fer. it I have learned to do.INF 'I have learned to do it.'

b. El pasaré a saludar. him I will pass by to greet 'I'll pass by to greet him.'

c. L' he baixat a buscar. him/her I have gone down to fetch.INF 'I have gone down to fetch him/her.'

Solà cites them as evidence against Cinque's proposal to treat light verbs as heads of functional projections, on the basis that they have too much lexical content to plausibly serve in this way. But their lexical richness is even more problematic for the featural representation of example (28).

The flatness of the featural representation also fails to account for 'respect for the tree', for which we have not only Alsina's examples above, but some additional ones from Solà (2002, p. 238):

a. Les pot aver vistes. them.F can.3SG have.INF see.PSTPART.FPL 'He/She can have seen them(F).'

b. Les ha pogudes veure. them.F have.3SG can.PSTPART.FPL see.INF 'He/She has been able to see them(F).'

c. Les ha pogudes anar a veure. them.F have.3SG can.PSTPART.FPL go.INF to see.INF 'He/She has been able to go to see them(F).'

Even if we accept the idea of representing each item with a feature, there is still the problem of getting the interpretation correctly determined by the order.

One could think of trying to do something with the notion of 'f-precedence', but, as far as I can work out, glue semantics does not include any way of saying something like 'if you are my semantic argument, I must precede you' in a situation where the structure is flat, 
and all items have the same f-structure and therefore s-structure. Andrews (2007) makes a proposal for a general principle, but it involved some additions to the theory, and did not get general uptake by the LFG community. Furthermore, it does not appear to be applicable to the problems with adjectival modifiers discussed in the previous section. But I claim that singleton sets with undersharing can solve all of these problems.

\subsection{A solution with hybrid objects and undersharing}

The proposal is that light verbs are introduced in the structures in (34) below: structure (a) applies when a right-branching VP seems indicated (Catalan and Spanish), whereas (b) applies when the verbs seem to form a cluster (French).

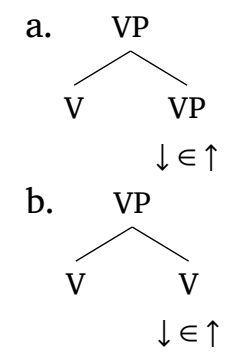

The orders are expected to be reversed in verb final languages, unless diachronic changes have occurred and made the rules more complex. Hindi/Urdu is an example with verb-final order and both (a) and (b) structures, but with the order of the daughters reversed (Butt 1995).

Superficially similar structures that do not in fact appear to involve clause-union can have the same c-structure form, but with the lower VP introduced as value of XCOMP, OBJ, or whatever else seems appropriate on the basis of the relevant evidence.

Now, example (27b) will get an f-structure like (35), with the grammatical relations shown as shared through all the levels. But we don't try here to represent the lexical specifications of the predicates for their arguments, because this involves issues of linking theory that we take up below: 
(35)

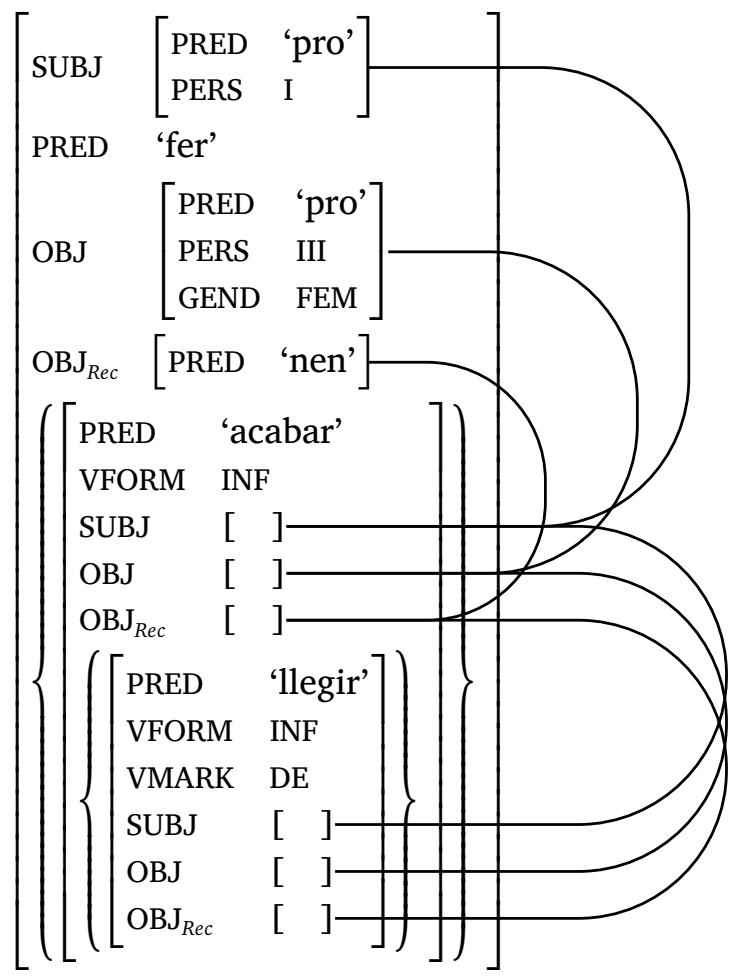

Form-determination can then be accomplished via the f-structure by specifications like these: ${ }^{14}$

(36) a. acabar: $(\uparrow \in \mathrm{VFORM})=\mathrm{INF},(\uparrow \in \mathrm{VMARK})=\mathrm{DE}$.

b. haber: $(\uparrow \in \mathrm{VFORM})=$ PASTPART, $\neg(\uparrow \in \mathrm{VMARK})$.

c. fer: $(\uparrow \in \mathrm{VFORM})=\mathrm{INF}, \neg(\uparrow \in \mathrm{VMARK})$.

The proposed structure therefore solves both of the problems discussed at the beginning of this section, with the provision that we need to treat the VFORM and VMARK as nondistributive. Nonetheless, they behave distributively in coordination, requiring undersharing in complex predicates, as we discuss in the next subsection.

\footnotetext{
${ }^{14}$ Note that they are technically functionally uncertain, due to the membership relation; notwithstanding, this is moot because the set is a singleton.
} 
We see in the following examples obligatory distribution of the infinitive VFORM and possibly optional distribution of VMARK:
a. acabà
de riure
i
(de) plorar.

finish.PRET.3SG VM laugh.INF and (VM) weep.INF

'He/she stopped laughing and crying.'

b. Quan acabis

de llegir l'article i

(de)

when finish.SUBJ.2SG VM read.INF the-article and (VM)

fer-ne el resum, avisa'm.

make-of it the summary, advise-me.

'When you finish reading the article and summarizing it, let me know.'

\section{(Alsina p.c.)}

Although both versions of (b) are acceptable, the one with the second de included is more formal, to the extent that, if omitted, it might be supplied by a copy editor (Alsina p.c.). We can account for this with two assumptions: first, that there is no undersharing of VMARK in coordinate structures; and second, that the verbal marker is introduced in a slightly higher projection than VP, either the higher or the lower able to be conjoined. Formal style prefers coordinating the higher one.

Distribution of infinitive, gerund and past participle VFORM in coordinate structures is illustrated here:

(38) a. La Maria fa riure i plorar el nen.

the Mary makes laugh and cry the boy

'Mary makes the boy laugh and cry.'

Alsina (1997, p. 222)

b. La Maria està rient i plorant.

the Mary is laughing and crying

(Alsina p.c.)

c. La Maria ha rigut i plorat.

the Mary has laughed and cried

(Alsina p.c.)

We can resolve the non-distribution issue by stipulating undersharing in the light verb VP rule, which can now be formulated as: 


$$
\begin{aligned}
& \rightarrow \quad \text { V } \quad \text { VP } \\
& \downarrow \in \uparrow / \text { VFORM /VMARK }
\end{aligned}
$$

These constructions were originally complement structures, which explains the undersharing stipulations, since features are not normally shared between complements and their heads.

Adverb placement constitutes a potential problem for the present treatment of distribution. The previous section and the discussion of frequency adverbs in Andrews (1983) indicate that the ADJUNCTS attribute is not distributive. However, Andrews and Manning (1999, p. 55) offer a contrary example:

(40) a. He fet beure el vi a contracor a la Maria. I have made drink the wine against $x$ 's will to the Mary 'I have made Mary drink the wine against her/my will.'

b. Volia tastar amb molt d'interès la cuina tailandesa. I wanted to taste with much interest the cuisine Thai 'I wanted to taste Thai food with much interest.'

(with much interest most naturally modifying want)

Catalan has the possibility of putting the object NP after the verb in simple clauses as well as restructuring ones. The two examples below are both fine without any obvious intonational peculiarities (Alex Alsina, p.c.), although the traditional doctrine is that the NP would normally go first:

a. entendràs les meves raons de seguida. understand.FUT.2SG the my reasons right away 'You'll understand my reasons right away.'

b. entendràs de seguida les meves raons. 'You'll understand my reasons right away.'

Further examples with the NP after an adverbial PP can be found on the web:

a. Llegiré amb calma tota la teva disertació. read.FUT.1SG with calmness all the your 'dissertation' 'I will read with calmness your entire 'dissertation'. ${ }^{15}$

\footnotetext{
15 http://hemeroteca.e-noticies.com/edicio-1168/popups/ popVerComentariosElemento_asp_idSeccion_3_idSubSeccion_id_ 2000633. htm; viewed 16 Feb 2018
} 
b. Llegeixo amb atenció el teu post. read.1SG with attention the your post 'I read (present tense) your post with attention.'16

Therefore, there is clearly a position for NPs at the end of the VP, after an adjunct PP. Also, since the OBJ grammatical relations are distributive, an NP can appear after an adjunct PP in the upper VP, while still functioning as the object of the lower verb. We can therefore explain the examples of (40) without having ADJUNCTS be distributive.

\section{4}

Linking theory

We now have almost everything we need except for a linking theory to account for the facts of subcategorization. There are a considerable number of options to choose from in the literature on these constructions, including those of Alsina (1996), Andrews and Manning (1999), and Andrews (2007). But here I will do something different, and propose an account of linking on the basis of the 'Kibort-Findlay Mapping Theory', henceforth KFMT, although I won't attempt a full integration of the analysis with that theory. KFMT is the development of the mapping theory of Kibort (2013) by Findlay (2016), also used in Asudeh et al. (2014). ${ }^{17}$ Its drawback for our purposes is that it has not yet been adapted to the demands of Romance languages, which show some differences from the Germanic and Bantu languages that most LFG lexical mapping theories other than Alsina's appear to be focused on. The reason for developing KFMT is that, unlike its predecessors, it is both fully within the formal theory of LFG, and capable of handling clause-union constructions.

The key to this capability is that it makes heavy use of glue semantics, in a way that allows it to deal in a straightforward way with the problem of suppressing the linking of the Agent argument of the Caused-verb to a subject grammatical function. Classic LMT works on a predicate-by-predicate basis, supplying grammatical relations to underspecified argument positions, which makes subject-suppression in complex predicate constructions difficult to achieve if they are viewed as actually having two predicates, while the proposals noted above, of

\footnotetext{
16 http ://interaccio.diba.cat/blogs/2015/intent - dapuntar - pros contres-gestio-comunitaria-cultura; viewed 16 Feb 2018

${ }^{17}$ I am indebted to Ash Asudeh for suggesting that I try this.
} 
Alsina on one hand and Andrews and Manning on the other, try to address this problem with devices that are not clearly and fully within the LFG formalism.

KFMT terminologically abandons the popular idea of 'argument structure', but replaces it with an elaboration of the 'semantic projection' of glue semantics. This is similar enough to argument structure that perhaps the concepts are being fused, rather than one replacing the other. The semantic projection is a projection from f-structure, and the novelty is to populate it with attributes such as $\mathrm{ARG}_{1}, \mathrm{ARG}_{2}$ and more, which reflect a classification of semantic roles in terms of their typical syntactic behaviour.

$\mathrm{ARG}_{1}$ is like the 'external argument' of GB/Minimalism, the 'I' of relational grammar, or the 'Actor' of Role and Reference Grammar, while $\mathrm{ARG}_{2}$ is like the non-oblique 'internal argument' of GB and Minimalism, the 'II' of Relational Grammar, or the 'Undergoer' of Role and Reference Grammar. $\mathrm{ARG}_{4}$ and above are obliques, while $\mathrm{ARG}_{3}$ is complicated, and will be discussed shortly. KFMT also uses Davidsonian event semantics, with an event variable. The meaning-constructor for a transitive verb such as llegir 'read' would be:

$$
\begin{gathered}
\lambda y x e . \operatorname{Llegir}(e) \wedge \operatorname{Agent}(x, e) \wedge \operatorname{Patient}(y, e): \\
\left(\uparrow_{\sigma} \mathrm{ARG}_{2}\right) \multimap\left(\uparrow_{\sigma} \mathrm{ARG}_{1}\right) \multimap\left(\uparrow_{\sigma} \mathrm{EV}\right) \multimap \uparrow_{\sigma}
\end{gathered}
$$

If this is added to a lexical entry that introduces the PRED-value 'llegir' into the f-structure, then we get the following pieces of $\mathrm{f}$ - and sstructure connected by the semantic projection $\sigma$ as the solution (the $\lambda$-term for the meaning not yet included):

$$
\left[\begin{array}{ll}
\text { PRED } & \text { 'llegir' }] \cdots
\end{array} \cdots \cdot\left[\begin{array}{lll}
\mathrm{EV} & {[} & ] \\
\mathrm{ARG}_{1} & {[} & ] \\
\mathrm{ARG}_{2} & {[} & ]
\end{array}\right]\right.
$$

The ' $\uparrow_{\sigma}$ ' at the end of (43) will associate the output of the meaningconstructor with the semantic projection of the f-structure in (44), but we need some additional machinery to associate the $\mathrm{ARG}_{i}$-values there with the grammatical relations that will express the arguments.

This is accomplished by the linking theory, which provides specifications of equations that equate the semantic projection of the bearer of a grammatical function with an $\mathrm{ARG}_{i}$ value. These specifications are 
highly compressed by templates. ${ }^{18}$ A relatively simple one is the template @ARG2, which is an abbreviation for instructions to optionally add the following specification to a lexical entry:

$$
<(\uparrow\{\mathrm{SUBJ} \mid \mathrm{OBJ}\})_{\sigma}=\left(\uparrow_{\sigma} \mathrm{ARG}_{2}\right)>
$$

In addition to the optionality of the whole equation as indicated by the angle brackets, there is an optional choice notated by the I within the equation, which allows for the object-to-subject 'promotion' that is a characteristic of the passive. The optionality of the equation allows for the NP argument to fail to be realized in f-structure, as long some other component of the lexical entry will provide a suitable meaning to the glue-semantics, as discussed by Asudeh et al. (2014). If this does not happen, then the glue assembly will fail due to resource deficiency.

A slightly more difficult example is the $\mathrm{ARG}_{1}$ specification, which expands to this:

$$
<\left(\uparrow\left\{\mathrm{SUBJ} \mid \mathrm{OBL}_{\theta}\right\}\right)_{\sigma}=\left(\uparrow_{\sigma} \mathrm{ARG}_{1}\right)>
$$

Here, $\mathrm{OBL}_{\theta}$ allows for the expression of an $\mathrm{ARG}_{1}$ as a prepositional phrase in the passive, with some additional facilities, not discussed here, optionally supplying this argument in the glue semantics if there is no by-object in $\mathrm{f}$-structure.

We will need a third kind of specification for the $a$-objects of Romance languages, which don't exactly fit into any of the categories developed in KFMT so far. I suggest that they are a variety of $\mathrm{ARG}_{3}$, which are generally taken to be objects that can alternate between OBJ and $\mathrm{OBJ}_{\theta}$. Romance languages don't appear to have evidence for any such alternation, at least at the level of overt form, ${ }^{19}$ so that in these languages, I suggest that $\mathrm{ARG}_{3}$ are the $a$-objects, which are how Romance languages spell out $\mathrm{OBJ}_{\theta}$. This gives us @ARG3 as abbreviating this specification:

$$
<\left(\uparrow \mathrm{OBJ}_{\theta}\right)_{\sigma}=\left(\uparrow_{\sigma} \mathrm{ARG}_{3}\right)>
$$

\footnotetext{
${ }^{18} \mathrm{~A}$ form of macro originally part of XLE implementation of LFG, but recently being explored more aggressively as an abbreviatory device for the linguistic theory.

${ }^{19}$ There are subtle arguments from the Minimalist Program that such alternations exist in languages where they are not morphosyntactically obvious, for example Anagnostopoulou (2003, pp. 230-234) on a-objects in Spanish.
} 
Then, by virtue of other parts of the grammar, $\mathrm{OBJ}_{\theta}$ is always realized as an $a$-object. With this background, we can consider the linking with restructuring predicates.

With intransitive light verbs such as aspectuals, the light verb has no effect on the available arguments; by extension, any theory that works for non-restructuring constructions will work for intransitive light verbs. But with the causatives we have the troublesome phenomenon of the Causee Agent being expressed as an object if the Caused verb is intransitive, but an $a$-object if it is intransitive:

(48) a. L' elefant fa riure les hienes. the elephant makes laugh.INF the hyenas 'The elephant makes the hyenas laugh.'

b. Els pagesos fan escriure un poema al follet. the peasants make write.INF a poem a.the elf 'The peasants make the elf write a poem.'

Furthermore, there is evidence that the Causee Agent is never in any way associated with the SUBJ-grammatical function, as discussed by Andrews (2007), who in turn further developed the arguments of Alsina (1996). So we need to completely suppress any possible linking of it to a SUBJ grammatical function.

The formal apparatus of KFMT allows us to do this by implementing an s-structure version of the glue semantics analysis provided in Asudeh (2005) of functional control by an argument of a higher verb. ${ }^{20}$ The idea is that if a predicate calls for an argument of type $e-t$, then any argument of that type which this applies to cannot accept any additional argument associated with the $e$, since this would cause 'resource surplus' in the glue semantics.

Therefore, the widely accepted 'three place causative' predicate can have a meaning-constructor like this:

$$
\begin{gathered}
\lambda P y x e . \text { Cause }(e) \wedge \text { Agent }(x, e) \wedge \text { Causee }(y, e) \\
\wedge(\exists d)(\text { Caused_Event }(d, e) \wedge P(y)(d): \\
{\left[\left(\uparrow \in \sigma \mathrm{ARG}_{1}\right) \multimap(\uparrow \in \sigma \mathrm{EV}) \multimap(\uparrow \in \sigma)\right] \multimap} \\
\left(\uparrow_{\sigma} \mathrm{ARG}_{\{2 \mid 3\}} \multimap-\left(\uparrow_{\sigma} \mathrm{ARG}_{1}\right) \multimap\left(\uparrow_{\sigma} \mathrm{EV}\right) \multimap \uparrow_{\sigma}\right.
\end{gathered}
$$

\footnotetext{
${ }^{20}$ Lowe (2015) also accomplishes complete subject suppression in a different way, which does not appear to be compatible with the present syntactic analysis, although it also employs KFMT.
} 
The first two lines represent the meaning, in Davidsonian event semantics, while the third line is the glue term for the VP 'Caused' argument, with open positions for the $\mathrm{ARG}_{1}$ and the event variable. The remaining arguments and the return of type $t$ appear on the final line. The first argument on this line can be either an $\mathrm{ARG}_{2}$ or an $\mathrm{ARG}_{3}$; this will be discussed below.

A typical constructor for a verb that this would apply to would be (43), repeated below for convenience:

(43) $\lambda$ yxe.Llegir $(e) \wedge \operatorname{Agent}(x, e) \wedge \operatorname{Patient}(y, e)$ :

$$
\left(\uparrow_{\sigma} \mathrm{ARG}_{2}\right) \multimap\left(\uparrow_{\sigma} \mathrm{ARG}_{1}\right) \multimap\left(\uparrow_{\sigma} \mathrm{EV}\right) \multimap \uparrow_{\sigma}
$$

If these are introduced in combination with the f-structure and s-structure of (50), their instantiated result would be (51), where labels are used to connect the semantic projection and glue literals:

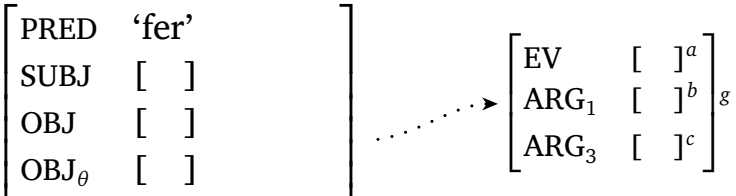

$$
\begin{aligned}
& \left\{\left[\begin{array}{ll}
\text { PRED } & \text { 'llegir' }] . .\}
\end{array}\right\}\right.
\end{aligned}
$$

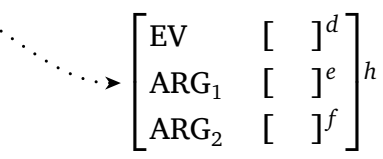

(51) a. $\lambda P y x e$.Cause $(e) \wedge \operatorname{Agent}(x, e) \wedge \operatorname{Causee}(y, e)$

$$
\wedge(\exists d) \text { (Caused_Event }(d, e) \wedge P(y)(d):
$$

$$
(e \multimap d \multimap h) \multimap c \multimap b \multimap a \multimap g
$$

b. $\lambda y x$ x.Llegir $(e) \wedge \operatorname{Agent}(x, e) \wedge \operatorname{Patient}(y, e)$ :

$$
f \multimap e \multimap d \multimap h
$$

Before we can apply (a) to (b) with implication elimination, we have to satisfy the first argument (label $f$ ) of (b), either by applying it to a 'real' argument such as perhaps War and Peace, or to a 'dummy' argument supplied as an assumption for later implication introduction; we'll represent the result of this with a w substituted for $y$ :

(52) $\lambda$ xe.Llegir $(e) \wedge \operatorname{Agent}(x, e) \wedge \operatorname{Patient}(\mathbf{w}, e)$ :

$$
e \multimap d \multimap h
$$


Now if we apply (51a) to (52) with implication elimination, we get the following after $\beta$-reduction:

$$
\begin{aligned}
& \lambda y x \text { e.Cause }(e) \wedge \operatorname{Agent}(x, e) \wedge \operatorname{Causee}(y, e) \wedge \\
& \quad(\exists d)(\text { Caused_Event }(d, e) \wedge \operatorname{Llegir}(d) \wedge \operatorname{Agent}(y, d) \wedge \\
& \quad \text { Patient }(\mathbf{w}, d)): \quad c \multimap b-a \multimap g
\end{aligned}
$$

The application of the causative verb to the Caused one is specified in terms of the s-structure and the $\in$ relationship in f-structure, and therefore can proceed without linking, but the NP arguments require this, to which we now turn.

In KFMT, the linking equations are optional, with the result that the Causee ARG $_{1}$ doesn't have to be linked to anything, which is good, because if it does try to link, this will cause assembly failure due to resource surplus. But the remaining ones either must link, or require some other meaning-constructor to match them up with something in meaning-assembly, as discussed by Asudeh et al. (2014).

Since this is an active sentence, there is no alternative to linking the Causer $\mathrm{ARG}_{1}$ with a syntactically represented argument. Therefore, the Causer Agent/ARG 1 must be a SUBJ, so the remaining $\mathrm{ARG}_{i} \mathrm{~s}$ must be apportioned between $\mathrm{OBJ}$ and $\mathrm{OBJ}_{\theta}$. If the caused verb is transitive, it will have an $\mathrm{ARG}_{2}$, whose only options are SUBJ and OBJ; the former is already taken, so it must get linked to OBJ. The Causer Object, on the other hand, will have to take its $\mathrm{ARG}_{3}$ option (as notated in (49)), and be realized as $\mathrm{OBJ}_{\theta}$. With an intransitive Caused verb, we encounter a problem, which is that constructor (49) provides two possibilities for its 'Caused' argument, $\mathrm{ARG}_{2}$ and $\mathrm{ARG}_{3}$, but only the former is possible. This requires a stipulation, which can be a (constraining) implication saying that if there is an $\mathrm{OBJ}_{\theta}$, there must be an $\mathrm{OBJ}$ :

(54) $\left(\uparrow \mathrm{OBJ}_{\theta}\right) \supset(\uparrow \mathrm{OBJ})$

It would be desirable if this could be a general constraint on Romance verbs, but there is a well-known class of verbs that violate it. These are the verbs that take dative objects with no accompanying accusative 'direct' object, such as, in Catalan, cridar 'shout at':

(55) En Ferran li crida.

the Ferran him.DAT shouts

'Ferran shouts at him.' (Alsina 1996, p. 172) 
I therefore propose that (54) is a specific constraint on causative verbs.

This analysis can also manage the 'long passives', that are found in Italian and Catalan, but not in Spanish or French (Alsina 1996, p. 187). According to Alsina (p.c.), passives of causatives don't sound truly natural, but sentences such as these below are possible:

(56) a. El pont ha estat fet enderrocar a un especialista the bridge has been made repair.INF by a specialist 'Someone has had the bridge repaired by a specialist (the repairer).' (c.f. (2) of Alsina 1996, p. 187)

b. El poema ha estat fet llegir al nen. the poem has been made read.INF a.the boy 'Someone has had the poem read by the boy.'

In these cases, if the causative verb is passivized, the $\mathrm{ARG}_{2}$ of the lower verb can be realized as the SUBJ, in accordance with the usual mapping rules. There is more to be said about valence alternation in restructuring-style causatives, but this should be enough to establish that combining KFMT with the present theory about f-structure is a viable prospect.

We have now shown how long passives, fusion of argument arrays, and clitic climbing work in our account, these being the three main aspects of the monoclausality that is the problematic feature of these constructions. These are all consequences of the claim that they have a single array of grammatical relations, shared across all the levels of complex predicate constructions. We now briefly consider Lowe's 2015 analysis of Hindi, which shows some similar phenomena in its causative constructions.

4.5

Lowe's 2015 analysis of Hindi

As we mentioned earlier, Lowe thoroughly and cogently critiques all previous analyses of restructuring complex predicates, relieving us of this rather demanding task. He then presents his own treatment of Hindi, where the main and all the light verbs correspond to the same f-structure, but the meaning-constructors introduced by the light verbs apply to each other and to that of the main verb so as to build a hierarchical interpretation. This works well for Hindi, and is in fully standard LFG + glue, but has some problems. The first, which we have 
already discussed, is that there are too many restructuring verbs in Catalan to plausibly treat them as not having PRED-features, but only being distinguished by some other kind of feature.

Another issue is that he says nothing about form-determination. As in Romance, different light verbs select different forms on their (in Urdu, linearly preceding) semantic complements. So completive le ('take') takes a (preceding) bare infinitive complement, while permissive de 'give' takes an oblique infinitive. This could be easily accommodated with the 'classic' m-projection from c-structure, but as we have noted, this proposal does not seem to find uses beyond the kinds of facts for which it was originally devised, and its subsequent adaptation to an m-structure that comes off f-structure is more complicated (I assume that having two kinds of $\mathrm{m}$-structure, one from cstructure, the other from f-structure, should be rejected unless there is overwhelming evidence in favor of it). Furthermore, the worked out adaptation, for French (Frank and Zaenen 2004), seems to assume a flat sequence of V's, while Butt (1995) argues that Urdu also has both these and also VP complement clause union structures, like those of Spanish and Catalan, but with the order reversed.

The last and most serious problem is that, as Lowe discusses on his pp. 438-441, his analysis cannot account for the dependence of the semantic interpretation on the hierarchical structure, because it depends on composing meaning-constructors connected to f-structure, which on his analysis of these constructions is flat rather than hierarchical. He accepts this as a deficiency, and observes that the attempt in Andrews and Manning (1999) to overcome it involved major changes to LFG, and furthermore didn't address the problem of adjective scope addressed in Andrews and Manning (1993). He is therefore willing to leave it as a 'long term problem'. The proposal of this paper, however, does overcome both problems, and with only small modifications to the current LFG framework, depending on which recent independent proposals are regarded as already accepted.

5

GONGLUSION

I have proposed modest extension to pre-existing ideas in LFG to solve some longstanding problems with the capacity of the theory. In terms of the formal architecture, it might be that there is no actual change 
at all, but only a change in the default structure-function mapping, with certain (possibly most or even all) kinds of c-structure heads marked by default with an $\downarrow \in \uparrow$ annotation rather than $\uparrow=\downarrow$. A remaining question is the treatment of PRED-features. For the analysis of restructuring predicates, we need PRED to be non-distributive, but this is not necessary for our analysis of modification, and Frank (2006) provides evidence from asymmetric coordination in German that PRED is distributive. If we decide the PRED is distributive, we can amend the analysis of Catalan by adding PRED to the undersharing specification of rule (39).

Observe that while the necessity for default nondistributivity of ADJUNCTS consists of subtle facts of interpretation and relatively rare grammatical phenomena, the stipulated nondistributivity of the verbal form features and possibly PRED is necessary to provide a reasonable analysis of the overt form of plentiful data, given the existence of clitic climbing and the other indications of 'monoclausality' (on this analysis, distribution/sharing of grammatical relations). So there would be a substantial Poverty of the Stimulus problem for stipulated nondistributivity of ADJUNCTS, but it is less serious for the stipulated nondistributivity of certain morphological features and maybe PRED, due to the more overt character of the evidence.

\section{ACKNOWLEDGEMENTS}

I would like to acknowledge Alex Alsina for a great deal of advice and judgements about Catalan, as well as an invitation to present the material at UPF Barcelona. Section 4 reproduces his analysis of Catalan data within a different framework. I am also indebted to Andrew Morrison, Mary Dalrymple, Adam Przepiórkowski, the members of the LFG glue semantics discussion group, and three anonymous JLM reviewers for useful feedback. I also acknowledge Christopher Manning, with whom I co-developed the precursors to the present proposal. Any errors, as usual, are mine. 


\section{APPENDICES}

A

THE REPRESENTATION OF DISTRIBUTED

ATTRIBUTES

Although the concept of distributive attribute has been around for some time, there does not appear to have been any explicit attempt to work it into the LFG solution algorithm as presented originally in Kaplan and Bresnan (1982, 273-274). Suppose we are processing the functional description for example (4). At some point we will encounter the annotation saying that the f-structure of the subject NP Mary is the SUBJ of the f-structure of the whole sentence. At this point, we might or might not know that this f-structure is a hybrid object, and if we do know this, we might or might not know what all of its members are. In order to be independent of processing order, the algorithm needs to proceed smoothly and monotonically in all cases. I suggest that a way to achieve this is to represent the f-structure of the subject explicitly as the SUBJ-value of the entire clausal f-structure, i.e. at the top level of the set-inclusion structure, as in (4b). Then, when the information to the effect that some f-structure is a member of the f-structure of the whole sentence beomes available, the information about distributive attributes of the whole can be copied into it.

On the other hand, there is a different situation that can arise when the value of some distributive attribute such as TENSE is specified the same way internally in each member. A reasonable strategy would be to do nothing, unless a constraining specification wants to check the value of the attribute in the entire structure; in this event, one would then check its value in the members. I doubt that doing more than this would facilitate processing. This leads to a slight discrepancy in the representation of distributive attributes in different situations, although I don't see how that would create any real problems.

An anonymous referee points out that constraining specifications bring out a difference between the attribute-based account of distributivity from Dalrymple (2001) and the property-based one of Dalrymple and Kaplan (2000), which is that under the latter conception, an existential constraint such as ( $f$ TENSE) will be satisfied if every member of a hybrid object $f$ has some TENSE value, even if they are not all the same, while under the former, it won't be. This is an interesting formal difference, but is unlikely to produce an empirically discernable 
effect, since we can always propose that TENSE is a structured attribute where there is always at a minimum a common sub-attribute such as + . The implemention suggested in the previous paragraph whereby constraints are only checked without any sharing being effected might allow the two conceptions to be combined in practice.

Stipulating non-distributivity of a compound attribute such as INDEX NUM, while INDEX GEND is to remain distributive, requires more complex arrangements than simple ones, but is not impossible. 
Here I will briefly show how to adapt Dalrymple's (2001) glue semantics for attributive adjectives to the present proposal. Sample constructors for the two modal adjectives former and confessed are:

(57) In both below, $\% G=($ ADJUNCTS $\in \uparrow)$ :

$$
\begin{aligned}
& \lambda P x . \text { Former }(P(x)):\left[\left(\% G \in_{\sigma} \mathrm{VAR}\right) \multimap\left(\% G_{\sigma}\right)\right] \multimap \\
& \left(\% G_{\sigma} \mathrm{VAR}\right) \multimap \% G_{\sigma} \\
& \lambda P x . \text { Confess }(x, P(x)):\left[\left(\% G \in_{\sigma} \mathrm{VAR}\right) \multimap(\% G \in)_{\sigma}\right] \multimap \\
& \left(\% G_{\sigma} \mathrm{VAR}\right) \multimap \% G_{\sigma}
\end{aligned}
$$

The changes from Dalrymple's (2001, p. 264) formulation are that the glue-side terms are a bit more complex in order to be able to apply the adjective meaning to that of the sister $\bar{N}$ and ascribe the result to the mother $\bar{N}$, and also the RESTR attribute is eliminated from the semantic projection, because it has no clear function. VAR should also be reconsidered, and its relationship to the widely proposed INDEX and CONCORD attributes established, but I won't do this here.

For intersectives, and similar, Dalrymple proposes two constructors, the first of which can be retained unaltered (other than the removal of RESTR), here illustrated by the one for Swedish:

$$
\lambda x . \operatorname{Swedish}(x):\left(\uparrow_{\sigma} \mathrm{VAR}\right) \multimap \uparrow_{\sigma}
$$

This is very close to what is needed for predicate adjectives. The other constructor that Dalrymple proposes is more complex, and effects the intersection of the adjectival meaning with the nominal meaning as constructed so far. Our version of it would be:

(59) $\% G=($ ADJUNCTS $\in \uparrow)$ :

$\lambda P Q x . P(x) \wedge Q(x):$

$\left[\left(\uparrow_{\sigma} \mathrm{VAR}\right) \multimap \uparrow_{\sigma}\right] \multimap\left[\left(\% G \in_{\sigma} \mathrm{VAR}\right) \multimap(\% G \in)_{\sigma}\right] \multimap\left(\% G_{\sigma} \mathrm{VAR}\right) \multimap \% G_{\sigma}$

Andrews (2010) suggests that this is a 'universal' meaning-constructor, similar in effect to the type-shifting rules widely employed in formal semantics. 
Sets, heads, and spreading in $L F G$

\section{REFERENGES}

Artemis Alexiadou (2017), Gender and Nominal Ellipsis, in Nicholas LACARA, Keir Moulton, and Anne-Michelle Tessier, editors, A Schrift to Fest Kyle Johnson, pp. 11-22, Open Access Publications 1, University of Massachussetts, Amherst MAURL: https://scholarworks.umass.edu/linguist_oapubs/1/.

Alex ALSINA (1996), The Role of Argument Structure in Grammar, CSLI Publications, Stanford, CA.

Alex ALSINA (1997), A Theory of Complex Predicates: Evidence from Causatives in Bantu and Romance, in Alex AlsinA, Joan Bresnan, and Peter SElls, editors, Complex Predicates, pp. 203-246, CSLI Publications, Stanford, CA.

Elena AnAgnostopoulou (2003), The Syntax of Ditransitives, de Gruyter, Berlin.

Avery D. ANDrEws (1983), A Note on the Constituent Structure of Modifiers, Linguistic Inquiry, 14:695-697.

Avery D ANDREWs (2007), Glue Semantics for Clause-Union Complex Predicates, in Miriam BUTT and Tracy Holloway KING, editors, The Proceedings of the LFG '07 Conference, pp. 44-65, CSLI Publications, Stanford CA.

Avery D. ANDREWs (2010), 'Grammatical' vs. 'Lexical' Meaning Constructors for Glue Semantics, in Yvonee TREIS and Rik De BUSSER, editors, Selected Papers from the 2009 Conference of the Australian Linguistic Society, The Australian Linguistic Society, URL:

http://WwW.als.asn. au/proceedings/als2009/andrews. pdf.

Avery D. ANDREws and Christopher D. MANNING (1993), Information-Spreading and Levels of Representation in LFG, Technical Report CSLI-93-176, Stanford University, Stanford CA, http://nlp.stanford.edu/ manning/papers/proj.ps; viewed 18 Feb 2018.

Avery D. ANDrews and Christopher D. MANning (1999), Complex Predicates and Information Spreading in LFG, CSLI Publications, Stanford, CA.

Ash AsUdeH (2005), Control and Resource Sensitivity, Journal of Linguistics, 41:465-511.

Ash AsudeH and Richard CROUCH (2002), Coordination and Parallelism in Glue Semantics: Integrating Discourse Cohesion and the Element Constraint, in Proceedings of the LFG02 Conference, in Miriam BUTT and Tracy Holloway KING, editors, pp. 19-39, CSLI Publications, Stanford, CA.

Ash Asudeh, Gianluca Giorgolo, and Ida Toivonen (2014), Meaning and Valency, in Proceedings of the LFG14 Conference, in Miriam BUTT and Tracy Holloway KING, editors, pp. 68-88, CSLI Publications. 
Oleg Belayev (2013), Optimal Agreement in Dargwa: Person at m-structure, in Tracy Holloway KING and Miriam BUTT, editors, Proceedings of the LFG13 Conference, pp. 90-110, CSLI Publications, Stanford, CA.

Oleg Belayev, Mary DALRYMPle, and John J. LOWE (2015), Number Mismatches in Coordination: An LFG Analysis, in Tracy Holloway KING and Miriam BuTT, editors, Proceedings of the LFG15 Conference, pp. 26-46, CSLI Publications, Stanford, CA.

Joan Wanda Bresnan, Ronald M. KAPlan, and Peter PETERSON (1985), Coordination and the Flow of Information through Phrase Structure, Unpublished manuscript.

Miriam ButT (1995), The Structure of Complex Predicates in Urdu, CSLI Publications, Stanford CA, originally Stanford Ph.D. dissertation, 1993.

Miriam BuTT, Tracy Holloway KING, Mará-Eugenia NiÑO, and Frédérique SEGOND (1999), A Grammar-Writer's Cookbook, CSLI Publications, Stanford CA.

Miriam BuTT, Maria Eugenia NiÑo, and Frédérique SEGOND (1996), Multilingual Processing of Auxiliaries within LFG, in Dafydd GibBon, editor, Natural Language Processing and Speech Technology, pp. 111-122, Mouton de Gruyter, Berlin.

Greville CoRbetT (1991), Gender, Cambridge University Press, Cambridge.

Greville G. CORBETT (1979), The Agreement Hierarchy, Journal of Linguistics, 15:203-224.

Mary DALRYMPLE, editor (1999), Syntax and Semantics in Lexical Functional Grammar: The Resource-Logic Approach, MIT Press, Cambridge MA.

Mary DALRYMPLE (2001), Lexical Functional Grammar, Academic Press, Cambridge MA.

Mary DALRYMPLE and Ronald M KAPLAN (2000), Feature Indeterminacy and Feature Resolution, Language, 76:759-798.

Jamie FINDLAY (2016), Mapping Theory without Argument Structure, Journal of Language Modelling, 4:293-338.

Annette FrANK (2006), A (Discourse-) Functional Analysis of Asymmetric Coordination, in Intelligent Linguistic Architectures: Variations on a Theme by Ronald M. Kaplan, in Miriam BUTT, Mary DALRYMPLE and Tracy Holloway KING, editors, pp. 259-285, CSLI Publications, Stanford CA.

Annette Frank and Annie ZAenen (2004), Tense in LFG: Syntax and Morphology, in Louisa SADLER and Andrew SPENCER, editors, Projecting Morphology, pp. 23-66, CSLI Publications, Stanford CA.

Ray S. JACKENDOFF (1977), $\bar{X}$-syntax, MIT Press, Cambridge MA. 
Ronald M. KAPLAN and Joan BRESNAN (1982), Lexical-Functional Grammar: a Formal System for Grammatical Representation, in Joan BRESNAN, editor, The Mental Representation of Grammatical Relations, pp. 173-281, MIT Press, Cambridge MA, also in Dalrymple et al., editors, 1995 Formal Issues in Lexical-Functional Grammar, CSLI Publications, pp. 29-130; page number references to 1982 version.

Ronald M. KAPLAN and John T. MAXWELL (1988), Constituent Coordination in Lexical-Functional Grammar, in Proceedings of COLING-88, vol I, pp. 303-305, also in Dalrymple, Kaplan, Maxwell and Zaenen (1995), pp 199-210.

Ronald M. KAPLAN and Jürgen WEDEKIND (1993), Restriction and Correspondence-Based Translation, in Proceedings of the Sixth European Converence of the Association for Computational Linguistics, pp. 193-202, Utrecht, URL: http : //Www . aclweb . org/anthology/E93-1024.

Anna KiBorT (2013), Objects and Lexical Mapping Theory [Abstract], in Miriam BUTT and Tracy Holloway KING, editors, Proceedings of the LFG13 Conference, CSLI Publications, Stanford CA.

Tracy Holloway KING and Mary DALRYMPLE (2004), Determiner Agreement and Noun Conjunction, Journal of Linguistics, 40:69-104.

Jonas KuHN (2001), Resource Sensitivity in the Syntax-Semantics Interface and the German Split NP Construction, in W. Detmar MEURERS and Tibor KISS, editors, Constraint-Based Approaches to Germanic Syntax, CSLI Publications, Stanford CA.

Idan LANDAU (2016), DP-internal Semantic Agreement: A Configurational Analysis, Natural Language and Linguistic Theory, pp. 975-1020.

John LowE (2015), Complex Predicates: an LFG + glue Analysis, Journal of Language Modelling, 3:413-462.

Christopher D. MANNING (1996), Romance Complex Predicates: In Defence of the Right-Branching Structure, paper presented at the Workshop on Surfaced-Base Syntax and Romance Languages, 1996 European Summer School on Logic, Language and Information, Prague. Draft available at URL:

https://nlp.stanford.edu/ manning/papers/right - paper . pdf; viewed 18 Feb 2018.

Jason MERCHANT (2014), Gender Mismatches under Nominal Ellipsis, Lingua, 151:9-32.

Rachel NORDLINGER and Louisa SADLER (2008), From Juxtaposition to Incorporation: an Approach to Generic-Specific Constructions, in Miriam BUTT and Tracy Holloway KING, editors, Proceedings of the LFG08 Conference, CSLI Publications, Stanford CA.

Sarah OUWAYDA (2014), Where Number Lies: Plural marking, numerals, and the collective-distributive distinction, Ph.D. thesis, USC, Los Angeles. 


\section{Avery D. Andrews}

Barbara PARTEE (2010), Privative Adjectives: Subsective plus Coercion, in Rainer BÄUERLE, Uwe REYLE, and Thomas Ede ZIMMERMANN, editors, Presuppositions and Discourse: Essays offered to Hans Kamp, pp. 273-285, Emerald Group Publishing, Bingley UK.

David Pesetsky (2013), Russian Case Morphology and the Syntactic Categories, MIT Press, Cambridge MA.

Zorica PUŠKAR (2017), Hybrid Agreement Modelling Variation, Hierarchy Effects and $\phi$-feature Mismatches, Ph.D. thesis, University of Leipzig, Leipzig, http://ling. auf. net/lingbuzz/003795.

Louisa SADler and Douglas J. ARNOLD (1994), Prenominal Adjectives and the Phrasal/Lexical Distinction, Journal of Linguistics, 30:187-226.

Louisa SADLER and Rachel NORDLINGER (2010), Nominal Juxtaposition in Australian Languages: an LFG Analysis, Journal of Linguistics, 46:415-452.

Jaume SolÀ (2002), Clitic Climbing and Null Subject Languages, Catalan Journal of Linguistics, 1:225-255.

Nikolaos Velegrakis (2011), The Syntax of Greek Polydefinites, Ph.D. thesis, University College London, London, http://discovery.ucl.ac.uk/1302548/1/1302548. pdf; viewed Feb 18, 2018.

Jean-Roger Vergnaud (1974), French Relative Clauses, Ph.D. thesis, MIT, Cambridge MA.

Stephen Wechsler (2011), Mixed Agreement, the Person Feature, and the Index/Concord distinction, Natural Language and Linguistic Theory, pp. 999-1031.

Stephen WeCHSLER and Larisa Zlatić (2000), A Theory of Agreement and its Application to Serbo-Croatian, Language, 76:799-832.

Stephen WeChSLER and Larisa Zlatić (2003), The Many Faces of Agreement, CSLI Publications, Stanford CA.

This work is licensed under the Creative Commons Attribution 3.0 Unported License. http://creativecommons .org/licenses/by/3.๑/ 